\title{
FUNDAMENTOS METODOLÓGICOS DA PESQUISA EM ENFERMAGEM
}

Maria Sumie Koizumi*

A metodologia de pesquisa em enfermagem tem sido objeto de muita atenção, principalmente depois que passamos a utilizar tanto os métodos quantitativos como os qualitativos de pesquisa.

Como diz DEMO (4), a ciência propõe-se a captar e manipular a realidade tal como ela é; que a atividade básica da ciência é a pesquisa. A metodologia, por sua vez, é uma preocupação instrumental: trata das formas de se fazer ciência. Cuida dos procedimentos, das ferramentas, dos caminhos.

Assim, não se deve superestimar a metodologia no sentido de cuidar mais dela do que de fazer ciência. O mais importante é chegarmos onde nos propomos a chegar, ou seja, a fazer ciência. Como chegar lá é também essencial mas, é especificamente instrumental. Somente o metodólogo faz dela sua razão de ser, principalmente o filosofo da teoria do conhecimento; para o cientista, em geral, ela constitui disciplina auxiliar o que, também, não deve ser interpretado como secundarização (4).

Outro aspecto diz respeito ao porque da metodologia de pesquisa em enfermagem. O que diferencia a pesquisa em enfermagem de outras disciplinas?

Do ponto de vista metodológico não há diferenças, já que o conhecimento e as habilidades requeridas para a pesquisa não variam de uma disciplina para outra. Entretanto, se olharmos para as diferentes dimensões da pesquisa, as distinções aparecem. Em qualquer disciplina deve haver consistência na orientação filosófica e na teoria daquela disciplina (2).

As orientações teóricas e o corpo de conhecimentos de uma disciplina definem as variáveis de estudo. As lacunas nesse corpo de conhecimentos determinam o que precisa ser conhecido. A congruência entre o que precisa ser conhecido, a orientação filosófica e as teorias definem o que é pesquisa em enfermagem (2). Sobretudo, deve haver correlação entre as necessidades da prática de enfermagem e a pesquisa.

Com estas considerações e abordando o tema estritamente sob o ponto de vista metodológico, propomo-nos tratar alguns aspectos que consideramos fundamentais no processo de pesquisa, quais sejam:

- a questão inicial de pesquisa;

- a seleção do método ou dos métodos para a mesma;

\footnotetext{
* Enfermeira. Professor Associado do Departamento de Enfermagem Médico-Cirurgica da Escula de Enfermagem da USP.
} 
- o domínio para a operacionalização das etapas do processo de pesquisa; dológico.

- a avaliação contínua do processo para que seja atingido o rigor meto-'

Há sempre uma história na evolução da pesquisa de uma dada disciplina, a partir do momento em que ela se torna uma realidade.

A pesquisa em enfermagem inicialmente só usou o método quantitativo e, durante certo perfodo, esta continuou sendo praticamente a única abordagem utilizada.

Alguns fatores influenciaram grandemente este predomínio nas pesquisas em enfermagem. Para Leininger citada por DUFFY (6) houve quatro importantes razões:

- os enfermeiros pesquisadores adotaram o modelo positivista prevalente como a base primária de suas atividades de pesquisa porque eles queriam ser aceitos e respeitados pela comunidade cientifica;

- esses enfermeiros implementaram os primeiros programas de doutorado em enfermagem e implantaram o paradigma quantitativo como modelo de pesquisa em tais programas;

- somente as pesquisas quantitativas eram aceitas para publicação;

- os fundos de auxílio às pesquisas eram concedidas somente para os projetos de pesquisa quantitativa.

Ao observarmos a evolução da pesquisa em educação podemos perceber alguns fatores muito semelhantes aos nossos.

Situado entre as ciências humanas e sociais, o estudo dos fenômenos educacionais não poderia deixar de sofrer as influências das evoluções ocorridas naquelas ciências. Por muito tempo, últimas quatro ou cinco décadas, somente os métodos quantitativos eram usados para a pesquisa em educação. Na última década, começaram a aparecer, entre os pesquisadores, sinais de insatisfação crescente em relação aos métodos empregados para responder às suas questōes de pesquisa. Isto deu origem a nqvas propostas de abordagem, com soluções metodológicas diferentes, na tentativa de superar pelo menos algumas das limitações sentidas na pesquisa que até então vinha sendo realizada em educação. A procura de novos caminhos de investigação trazia no seu âmago uma legítima e dominante preocupação com os problemas de ensino (10).

Movimento semelhante, ocasionado pela insatisfação decorrente do uso exclusivo do método quantitativo, o qual não respondia às expectativas do pesquisador enfermeiro no que tange aos problemas a pesquisar, motivou a busca de métodos que pudessem responder satisfatoriamente a essas questões. Assim, os métodos qualitativos passaram também a compor o cenário da pesquisa em enfermagem.

Um aspecto que, acreditamos, merece ser ressaltado, diz respeito a quem está fazendo pesquisa em enfermagem. No Brasil, e acreditamos que também em outros países, a pesquisa em enfermagem foi altamente incrementada com o advento da pós-graduação "sensu estrito", ou seja, dos programas de Mestrado e Doutorado. Grande parte da produção de pesquisa é oriunda desses programas. Isto significa que a produçâo de pesquisa em enfermagem vem sendo fortemente intermediada pela pós-graduação, não só no produto como, também, no processo de ensino/aprendizagem de métodos de pesquisa. Significa, igualmente, que a res- 
ponsabilidade da escola é pelo menos dupla, pois ela começou e continua tendo um papel muito importante nos caminhos da evolução da pesquisa em enfermagem.

É também importante enfatizar que há consenso entre as autoras sobre a complementaridade dos métodos quantitativo e qualitativo, pois geram diferentes tipos de conhecimentos úteis para a prática da enfermagem; sobretudo, ressaltam que o problema a ser estudado é que determina qual o método a ser utilizado para aquela pesquisa.

Considerando que o método científico incorpora todos os procedimentos usados pelos cientistas para a aquisição de conhecimentos, depreende-se que ele inclue os métodos quantitativo e qualitativo de pesquisa (2).

O método quantitativo é um processo formal, objetivo e sistemático, segundo o qual os dados numéricos são utilizados para obter informaçôes acerca do mundo. Este método de pesquisa é usado para descrever, testar relações e determinar causas.

O método qualitativo é uma abordagem sistemática, subjetiva, usada, para descrever as experiências de vida e dar-lhes significado. Ele vem sendo utilizado pelas ciências sociais e comportamentais há muito tempo, sendo que, na enfermagem o interesse por esse método data da década de 70. Ele focaliza a compreensão do global a qual é consistente com a visão holística da enfermagem.

Cada um dos métodos engloba diferentes tipos de pesquisa.

Nos métodos quantitativos estão incluídos os seguintes tipos de pesquisa:

- exploratória

- descritiva

- correlacional

- comparativa

- quase experimental

- experimental

É bastante interessante a classificação utilizada por BRINK \& WOOD (1) sobre estes tipos de pesquisa, baseada no princípio do controle que, por sua vez, baseia-se no nível de conhecimento existente sobre o tópico e o grau de controle passível de ser exercido pelo pesquisador sobre as variáveis em estudo. Elas apresentam três níveis básicos de "design" e seus tipos de pesquisa.

Nivel III: experimental

- experimental

- quase-experimental

Nivel II: "survey"

- comparativo

- correlacional

Nível I: exploratório-descritivo

- descritivo

- exploratório

Teoricamente, quanto mais alto for o nível do "design" da pesquisa, maior é o grau de controle e o nivel do conhecimento existente acerca das variáveis. $O$ nível de conhecimento acerca das variáveis é maior ao nível do experimento e é esperado que seja muito limitado no nível exploratório. Assim, a escolha do tipo de pesquisa depende do conhecimento existente sobre o tópico a ser estudado e o 
conhecimento gerado refere-se à descrição dos fatos, relação entre as variáveis ou ao estabelecimento de causa e efeito do fenômeno.

Há indicação do uso de pesquisas do tipo experimental ou quase-experimental quando a relação causal entre as variáveis pode ser tanto predita como eticamente testada. Se o pesquisador acreditar que as variáveis do seu estudo estão relacionadas e os resultados de sua interação estão preditos, mas há impedimento ético para a manipulação das variáveis, deve-se usar a pesquisa comparativa. Aliás, está é bastante utilizada principalmente nas pesquisas clínicas. Se o pesquisador tem um conhecimento descritivo básico acerca das variáveis mas não sabe se elas estão relacionadas, a melhor escolha será a pesquisa do tipo correlacional. Se, por outro lado, uma variável ou conceito vem sendo explorado mas não há informação sobre sua existência em uma dada população, a pesquisa descritiva é considerada a mais apropriada. Finalmente, se há conhecimento muito limitado ou se ele inexiste naquele tópico, a pesquisa exploratória é a mais adequada.

O controle das variáveis e a predição de suas ações requer um vasto conhecimento. Se o resultado da pesquisa não pode ser predito e sustentado com teoria, não é ético desenvolver o experimento com sujeitos vivos. Além disso, o nível do "design" está fundamentado no conhecimento acerca da operacionabilidade das variáveis no tópico e o grau de controle que pode ser exercido pelo pesquisador sobre estas variáveis, no próprio processo de pesquisa.

Nos métodos qualitativos estão também incluídos vários tipos de pesquisa, sendo alguns mais freqüentemente adotados na enfermagem $(2,7,12,14)$. Dentre eles podemos citar:

- a fenomenológica

- a fundamentada nos dados (grounded theory)

- a etnográfica

Devido à singularidade da abordagem qualitativa elas são, em geral, consideradas separadamente, embora também guardem pontos comuns.

Alguns pressupostos são comuns a esses tipos de pesquisa.

- O ambiente natural como sua fonte direta de dados e o pesquisadorr como seu principal instrumento e por isso ser chamado de naturalístico;

- Os dados coletados são predominantemente descritivos;

- A preocupação com o processo é muito maior do que com o produto;

- O significado que as pessoas dão às coisas e à sua vida são focos dee atenção especial do pesquisador. Há sempre uma intenção de captar a perspectiva dos participantes, ou seja, a maneira como os informantes encaram as questões que estão sendo focalizadas;

- A análise dos dados tende a seguir um processo indutivo. $O$ pesquisador não se preocupa em buscar evidências que comprovem hipóteses definidas antes do início do estudo. As abstrações se formam a partir da inspeção dos dados num processo de baixo para cima.

Para apontar algumas diferenças entre os tipos de pesquisa mencionados, resumidamente podemos dizer que:

- na pesquisa fenomenológica a abordagem é indutiva, descritiva, desenvolvida da filosofia fenomenológica cujo foco é a compreensão das respostas globais do ser humano e não somente a compreensão de partes ou comportamentos específicos. O objetivo da fenomenologia é descrever a experiência tal como ela realmente se apresenta ou é experienciada. O pesquisador deve abordar o fenó- 
meno a ser explorado sem expectativas ou classificações pré-concebidas. A meta é descrever a estrutura sistemática total da experiência vivida, incluindo o significado que estas experiencias tem para os indivíduos que dela participaram.

- na teoria fundamentada nos dados (grounded theory) há uma abordagem metodológica dirigida ao desenvolvimento de teoria, sem qualquer compromisso particular com tipos específicos de dados, linhas de pesquisa ou interesses teóricos. É muito usada para desvendar quais os problemas que existem num dado meio e como as pessoas nele envolvidas interagem. Ela enfatiza a observação e o desenvolvimento intuitivo da relação entre as variáveis. Envolve formulação, teste e redesenvolvimento de proposições até evoluir para uma teoria.

- na etnográfica busca-se investigar a cultura através de um estudo aprofundado dos membros desta cultura. Este tipo de pesquisa atenta para contar a história da vida diária daquela população e descrever a cultura da qual ela faz parte. $O$ processo envolve uma coleta sistemática, análise e descrição dos dados para desenvolver uma teoria de comportamento cultural. $O$ pesquisador vive ou torna-se parte do local daquela cultura para obter os dados. Ele descreve culturas específicas e também compara culturas para determinar as semelhanças e as diferenças existentes.

É importante ressaltar que, no Brasil, o desenvolvimento de pesquisas fenomenológicas, etnográficas e fundamentada em dados é bastante importante. Há áreas de pesquisa bem definidas em diferentes estágios de desenvolvimento e de consolidação que nos têm fornecido dados valiosos, seja de ordem metodologica seja de geração de conhecimentos. Além destas, há também aquelas com uso de outras vertentes metodológicas da dialética como a fundamentada no materialismo histórico, entre outras.

Escolher o método e o tipo de pesquisa mais adequado para aquela questão inicial de pesquisa ou problema já bem delimitado não é tarefa simples.

Como já mencionado, é recomendável que ela seja compartilhada com pesquisadores que atuem naquela área de conhecimento e que tenham domínio sobre os métodos de pesquisa que poderiam ser indicados para aquele estudo. Minimamente, deve ser o resultado do trabalho conjunto do orientando e do orientador, se a nível acadêmico, aliás como em todo desenvolvimento do processo de pesquisa.

Escolhido o método e o tipo de pesquisa, conhecer cada uma de suas etapas e, principalmente, estar apto para desenvolvê-las, são condições imprescindíveis. Basicamente há três etapas a saber:

$$
\begin{aligned}
& \text { 1a - Planejamento } \\
& 2^{\mathbf{a}} \text { - Execução } \\
& \text { 3a - Divulgação }
\end{aligned}
$$

Na 1a etapa há vários passos a serem seguidos. Alguns podem ser desnecessários e outros precisam ser mais reforçados de acordo com o nível e tipo da pesquisa. Particularmente na etapa de planejamento é uma constante a necessidade de modificar, de re-pensar, de reformular.

A $2^{\text {a }}$ etapa depende grandemente da operacionalização ou da profunda reflexão feita na $1^{\text {a }}$ etapa. O domínio da metodologia e sua aplicação no estudo que se pretende desenvolver é muito importante para o sucesso da etapa de execução. Se a coleta de dados, o preparo dos dados coletados para análise, a análise dos dados e a interpretação dos resultados serão feitas consecutivamente ou si- 
multaneamente, dependerão do método selecionado. Isto aplica-se também ao como os dados serão tratados, se numericamente ou textualmente.

É na 1⿳亠丷厂 etapa que já projetamos como será a 3ạa, a de divulgação. Uma pesquisa não estará completa se seus achados não forem divulgados. A comunicação da pesquisa envolve a disseminação dos resultados para a população apropriada, que inclui os enfermeiros, os profissionais da área de saúde e o consumidor do cuidado com a saúde. Os meios mais comumente usados são em congressos ou similares, por meio de comunicações orais e "posters" e as publicações seja em livros, anais de congressos ou, principalmente, em periódicos específicos.

Julgar-se apto a desenvolver cada uma das etapas do processo de pesquisa não é suficiente. $O$ rigor metodológico deve ser medido durante todo o processo para qualificar a pesquisa.

Este $e$ um aspecto que merece reflexão profunda e que certamente seria impossível ser esgotada neste curto espaço de tempo disponível.

O rigor metodológico pode ser analisado com relação à pesquisa, ou como foi pesquisado e ao pesquisador ou quem conduziu a pesquisa. Ambos são essenciais para se alcançar o rigor.

Os critérios de avaliação do rigor da pesquisa propriamente dita devem estar estabelecidos e estes devem ser coerentes com o método de pesquisa adotado.

Considerando a existência de características específicas que diferenciam a pesquisa quantitativa da qualitativa é preciso que elas sejam respeitadas na avaliaçáo do rigor metodológico. Neste sentido, é interessante a análise da súmula apresentada por BURNS; GROVE (2) mostrando ponto por ponto as diferenças existentes nas pesquisas quantitativas e qualitativas.

Quadro I - Características das pesquisas quantitativas e qualitativas.

\begin{tabular}{ll}
\hline PESQUISA QUANTITATIVA & PESQUiSA QUALITATIVA \\
\hline - Ciência " hard" & - Ciência" soft" \\
- Foco; conciso e limitado & - Foco: complexo e aberto \\
- Reducionista & - Holístico \\
- Objetivo & - Subjetivo \\
- Raciocinio: lógico dedutivo & -Raciocinio: dialético, indutivo \\
- Base de conhecimento: relaçăo & - Base de conhecimento: \\
causa e efeito & significado, descoberta \\
- Testa teorias & - Desenvolve teoria \\
- Controla & - Compartilha interpretação \\
- Instrumentos especificos & - Comunicação e observação \\
- Elemento básico de análise: & - Elemento básico de análise: \\
números & palavras \\
- Análise estatística & - Interpretação individual \\
- Generalização & - Singularidade \\
\hline
\end{tabular}

Fonte: BURNS, N.: GROVE, S. K. The practice of nursing research: conduct, critique and utilization. Philadelphia, W. B. Saunders, 1987. p. 36. 
Ėmbora seja um quadro sumário extremamente simplista ele mostra pontos básicos dos dois métodos.

Para essas autoras (2) a pesquisa quantitativa é considerada uma ciência"hard" pois está baseada no rigor, objetividade e controle. Derivada de um ramo da filosofia chamado positivismo lógico, opera com regras estritas da lógica, da verdade, das leis, dos axiomas e das predições. A pesquisa qualitativa é considerada uma ciência "soft" ou uma abordagem filosófica ou artística, que evoluiu das ciências comportamental e social, como um método para compreensão da natureza humana singular, dinâmica e holística.

Assim como há autores que discordam desta classificação em ciência " hard " e "soft" (3), nós também a julgamos inconveniente, pois perpetua a idéia de que a análise por números é superior àquela com palavras, quando na verdade não há termo de comparação entre ambas.

O foco da pesquisa quantitativa é identificado como conciso, limitado e reducionista. A objetividade é um traço marcante e o não envolvimento do pesquisador no estudo é essencial. O foco da pesquisa qualitativa, por sua vez, é complexo e aberto e é propósito da pesquisa dar significação de conjunto, ou seja, holístico. $O$ pesquisador é parte do estudo e nesta abordagem assume-se que a subjetividade é essencial para a compreensão das experiências humanas.

A pesquisa quantitativa é conduzida para a descrição de variáveis, identificação da relação entre as mesmas e exame da relação de causa e efeito. É portanto um método muito útil para testar teorias; o pesquisador utiliza o raciocínio dedutivo e lógico para examinar o particular e chegar às generalizações. A pesquisa qualitativa é conduzida para gerar conhecimentos concernentes ao significado e descoberta. O pesquisador utiliza, predominantemente, o raciocínio dialético e indutivo. Como na pesquisa qualitativa há busca do significado, os achados podem ser usados para identificar a relação entre as variáveis, e estas afirmações de relação são usadas no desenvolvimento de teorias.

A pesquisa quantitativa requer controle. $O$ pesquisador usa o controle para identificar e limitar o problema a ser pesquisado e estabelece limites sobre as variáveis em estudo com o objetivo de facilitar um exame mais preciso das mesmas; usa instrumentos ou equipamentos para gerar dados numéricos e usa a análise estatística para organizar os dados e determinar a relação significante. $O$ controle, os instrumentos e a análise estatística buscam a precisão. A generalização dos resultados depende da população em estudo e o pesquisador deve ser bem cauteloso ao fazê-la.

$\mathrm{Na}$ pesquisa qualitativa, o pesquisador usa observações estruturadas ou não e comunicação como o meio para obtenção de dados. Nos dados há interpretação compartilhada entre pesquisador e sujeitos do estudo e nenhuma tentativa é feita para controlar esta interação. Os dados qualitativos são gerados na forma de palavras e são analisados em termos de respostas individuais ou sumários descritivos ou ambos. O pesquisador identifica as categorias organizando e classificando os dados. O objetivo da análise é organizar os dados para lhes dar significação, interpretação individualizada ou estrutura que descreva o fenomeno estudado. Os achados do estudo qualitativo são únicos para aquele estudo e não é objetivo do pesquisador generalizá-lo para a população. Contudo, a compreensão do significado do fenômeno numa situação particular é útil para a compreensão dos fenômenos similares em situações similares. 
Retomando a avaliação de rigor metodológico, nota-se que a validade, a fidedignidade e a objetividade são aspectos muito valorizados nos métodos quantitativos.

A mensuração desses aspectos está fundamentada no "design" das pesquisas quantitativas com critérios bem definidos o que lhes conferem alta coerência e facilidade de aplicação. Há sobretudo, farta literatura de metodologia de pesquisa ou, especificamente, de metodologia de pesquisa em enfermagem abordando a avaliaçãe do rigor metodológico neste método. Cumpre porém, mencionar que isto não significa terem estes critérios sido rigorosamente obedecidos.

Numa visão mais ampla quanto à avaliação do rigor metodológico, poderse-ia categorizar alguns fatores que fossem comuns aos métodos de pesquisa e que contivessem critérios específicos, de acordo com o método utilizado.

Neste enfoque, Guba; Lincoln citados por SANDELOWSKI (16), analisam quatro fatores relacionados com os testes de rigor, a saber, veracidade, aplicabilidade, consistência e neutralidade, os quais seriam medidos pela validade interna e externa, fidedignidade e objetividade quando usado o método quantitativo.

Nos métodos quantitativos a veracidade é avaliada quanto ao manejo da validade interna e pela validade dos testes e instrumentos usados para mensurar 0 fenomeno sob investigação. A validade interna é obtida quando há confiança de que os achados do estudo devem-se às variáveis em estudo e não ao procedimento de investigação. Por outro lado, um instrumento de pesquisa é válido quando há certeza de que ele mediu o que foi pré-estabelecido para ser medido.

Pela validade externa avalia-se a extensão da aplicabilidade. Os resultados ; e procedimentos do estudo são externamente válidos quando há segurança de que os vieses de seleção, os efeitos dos pré-testes, de estar no estudo e dos multi-testes sobre a população de estudo não produziram condições não comparáveis com a ocorrência natural. Ainda dependendo da validade interna do estudo, a validade externa refere-se à generalização dos achados e à representatividade dos elementos de estudo, dos testes e das situações testadas.

Paradoxalmente, quanto mais controlado é o estudo mais difícil é aproximá-lo daquelas condições reais da vida e isto interfere na generalização.

Algumas regras de amostragem são observadas para assegurar a representatividade e a generalização. Nelas incluem-se a amostra randomizada, a randomização na composição dos grupos controle e de estudo e a pré-determinação do tamanho da amostra para assegurar a inferência estatística.

A fidedignidade diz respeito à consistência, estabilidade e significância do teste ou dos procedimentos em teste. Ela confere consistência ao estudo. A fidedignidade é pré condição para a validade. A replicação é meta inerente à fidedignidade. A repetição dos procedimentos em teste e os resultados levam à credibilidade dos achados e segurança na generalização do estudo.

A objetividade é uma forma de neutralidade exercida pelo pesquisador e é alcançada quando a fidedignidade e a validade estão estabelecidas. Para alcançar a objetividade há crença de que a distância entre o pesquisador e seus elementos de estudo e dados deve ser mantida. A idéia da objetividade na pesquisa quantitativa, repousa sobre o pressuposto de que há um conhecedor e coisas a serem conhecidas e que a relação entre elas deve ser caracterizada pela separação e distanciamento. O contato entre o investigador e o que deve ser investigado é mediado 
e controlado por protocolos, teorias e instrumentação.

Retomando o enfoque de Guba; Lincoln, os mesmos quatro fatores são também usados nos métodos qualitativos mas, para sua aplicação, é necessário que haja adaptação nos critérios de medida.

Desta forma, a veracidade seria avaliada pela credibilidade, a aplicabilidade pela adequação, a consistência pela verificabilidade e a neutralidade pela confirmação.

A credibilidade é obtida quando são apresentadas interpretações ou descrições fiéis da experiência humana, de tal forma que as pessoas a elas submetidas possam reconhecê-las como suas próprias descrições ou interpretações.

A adequação é encontrada quando os achados da pesquisa ajustam-se em contextos fora daquela situação de estudo, ou quando esses achados são vistos como significativos e aplicáveis em termos de suas próprias experiências. Os achados são bem fundamentados nas experiências de vida estudadas e refletem seus elementos típicos e atípicos.

A verificabilidade é alcançada quando outro pesquisador pode claramente : seguir a "trilha de decisão" usada pelo investigador. Além disso, um outro pesquisador poderia chegar às mesmas conclusões ou a elas comparáveis pelos dados, perspectivas e situações daquele pesquisador.

A confirmação ou confirmabilidade é atingida quando os três critérios anteriores, ou seja, credibilidade, adequação e verificabilidade estão bem estabelecidos.

Considerando que os aspectos especificos que asseguram a comprovação do estudo dependem:

- do tipo de evidências usadas (relato oral, sujeitos, dados observados, , artefatos, documentos pessoais e públicos),

- das técnicas empregadas para coleta de dados (entrevista, observação,, observação participante), de teorias),

- dos objetivos do estudo (descrição, explanação, geração ou verificação )

- das técnicas de análise empregadas (indução analítica, método de com- . paração constante, análise literária).

SANDELOWSKI (16) operacionaliza estratégias que possam ser usadas em vários tipos de pesquisas qualitativas mas, particularmente naquelas que analisam o homem como sujeito.

Para ela (16), a verificabilidade é alcançada especificamente pela descrição, explanação ou justificação dos seguintes pontos:

- como o pesquisador interessou-se pelo sujeito do estudo;

- como o pesquisador vê o que foi estudado;

- os objetivos do estudo;

- como os sujeitos ou as peças de evidéncia foram incluídas no estudo e : como eles foram abordados;

- o impacto que os sujeitos ou evidéncias e o pesquisador tiveram um em I relação ao outro;

- como os dados foram coletados;

- quanto durou a coleta de dados;

- onde os dados foram coletados; 
- como os dados foram reduzidos ou transformados para a análise, inter-pretação e apresentação;

- como os vários elementos dos dados foram valorizados; ter os dados;

- como foi a inclusão ou exclusão das categorias desenvolvidas para con--

- quais foram as técnicas especificas usadas para a determinação da cre-dibilidade e adequação dos dados.

Ao pesquisador caberia ainda avaliar seus dados brutos, sistema de codificação e categorização dos dados e como os diferentes elementos dos dados foram ligados um ao outro.

A verificabilidade é demonstrada primariamente no relatório de pesquisa. Conseqüentemente, a existência de um material avaliável contendo todas as fases do estudo qualitativo é essencial para o processo de auditagem.

A credibilidade e a adequação do estudo qualitativo dependem de váriass estratégias especificas. Estas estratégias seriam planejadas para controle dos três maiores riscos de credibilidade e propriedade do estudo: a falácia holística, os vieses de elite e a ocorrência natural. Elas incluem:

- checar a representatividade dos dados como um todo e as categoriass codificadas e os exemplos usados para reduzir e apresentar os dados;

- cruzar as fontes de dados e os procedimentos de sua coleta para deter-minar a congruência dos resultados;

- checar as descrições, as explanações e as teorias de forma a assegurar at presença dos elementos típicos e atípicos;

- obter validação pelos próprios sujeitos do estudo.

Para completar, acrescenta que o prolongado contato do pesquisador com os sujeitos e a análise dos dados por outro pesquisador poderiam ajudar na validação dos resultados.

Como já mencionado, o pesquisador é também elemento essencial para o rigor metodológico. Suas características pessoais podem influenciar ou ser influenciadas no processo de pesquisa. Isto significa que as qualidades do pesquisador, enquanto características específicas devem ser além de auto-reconhecidas, estimuladas, desenvolvidas e valorizadas no processo de pesquisa.

Nos métodos quantitativos, o pesquisador esforça-se constantemente por chegar a instrumentos precisos de medida e projetos rigorosamente controlados. As características valorizadas incluem o exame crítico do raciocínio e a atenção para a precisão. O processo de raciocínio logístico e dedutivo são considerados essenciais e visam diminuir erros em áreas como as de medida, "design", análise estatística e generalização. Há um controle imposto pelo pesquisador relacionado com a identificação do problema, o "design" e a análise estatística.

Nos métodos qualitativos, o pesquisador, no processo de pesquisa usa sua personalidade no processo de pesquisa e isto é considerado um fator chave. A empatia e a intuição são usadas deliberadamente e estas habilidades são cultivadas. Ele deve estar intensamente envolvido com as experiencias do sujeito a fim de interpretá-lo; deve permanecer aberto às percepções do sujeito mais do que tentar compor o significado pelas suas proprias experiencias.

Ao analisar alguns aspectos metodológicos das pesquisas quantitativas e qualitativas, por meio das suas diferenças, poder-se-ia caminhar simplesmente para a acentuação da dicotomização já existente. Mas o nosso intuito foi no sen- 
tido de apontar as bases metodológicas de cada uma delas, ou seja, o que as diferencia enquanto meio para atingir a finalidade de uma disciplina.

A enfermagem enquanto disciplina, fundamenta-se no cuidado do ser humano, na sua totalidade ou globalmente. Desde suas raízes, o conceito do todo sempre foi muito forte e direcionou seu desenvolvimento. Se num dado momento histórico, em que a pesquisa em enfermagem foi enfocada com mais vigor, houve predomínio quase absoluto dos métodos quantitativos, era esperado que a visão holística da assistência fosse também resgatada para a pesquisa, até mesmo para manutenção da coerência da disciplina.

Por outro lado, a problemática envolvida na prática da enfermagem náo poderia ser resolvida simplesmente pela opção por um ou outro método de pesquisa.

Nesse sentido, o uso combinado de métodos quantitativos e qualitativos tem sido bastante discutido. Esta combinação poderia ocorrer seqüêncialmente ou simultaneamente.

No uso seqüêncial o projeto seria iniciado com métodos qualitativos até as hipóteses emergirem. No estágio de testes da hipóteses, passar-se-ia para o método quantitativo.

No uso simultâneo os dois métodos seriam aplicados endereçados ao mesmo problema.

A combinação de métodos é denominada triangulação. Tem defensores assim como autores que the são contrários Convencionalmente, entende-se que ela envolve variedade de dados, de pesquisadores, de teorias, assim como de metodologia (5).

A triangulação de dados ocorre quando os pesquisadores usam múltiplas fontes de dados como possíveis para examinar aquele evento. Ela pode ocorrer em relação ao tempo, espaço ou pessoa. MITCHELL (11) a exemplifica num estudo acerca do desejo de comer. Os dados foram coletados de mulheres em diferentes dias da semana, durante diferentes meses, diferentes fases do ciclo menstrual e diferentes períodos do dia. Os dados de cada dia, eram registrados num diário e versavam sobre o desejo de comer e comportamento de comer, num período minimo de 90 dias consecutivos. Dados acerca da ingestão de alimentos eram também coletados durante duas diferentes fases do ciclo menstrual, assim como em diferentes dias da semana.Auto-relatos retrospectivos bem como diários concorrentes, eram também obtidos. Aqui, os diferentes períodos de tempo compuseram a triangulação de dados. O ponto central foi que todas as fontes de dados tinham um foco similar, ou seja, elas relatavam algum aspecto da experiência do desejo de comer.

Pode haver também, triangulação de pesquisadores, que consiste em múl- tiplas observações do objeto de pesquisa por diferentes investigadores. No estudo sobre desejo de comer, dois pesquisadores coletaram os dados sendo que, um usou a entrevista semiestruturada por telefone e o outro, dados retrospectivos, levantados na forma de respostas com alternativas fechadas.

A triangulação teórica consiste no uso de múltiplas perspectivas em relação ao mesmo conjunto de objetos. Os dados podem ser abordados com múltiplas hipóteses de forma que vários pontos de vista teóricos possam tomar lugar lado a lado e seu poder relativo pode ser avaliado. Várias alternativas explanatórias do fenômeno, cada um com diferentes bases teóricas mas interrelacionadas, são con- 
sideradas conjuntamente e testadas dentro do mesmo corpo de dados. No estudo sobre o desejo de comer, vários domínios estiveram representados, a saber: o domínio psicológico, quando foram testadas as hipóteses dos estados cognitivo e afetivo; o domínio sociológico ao serem testadas as hipóteses do contexto social; e, o domínio fisiológico quando foram testadas as hipóteses dos ciclos nutricional e mestrual. No conjunto, estas diferentes hipóteses, cada qual representando diferentes explicações para o desejo de comer, exemplificam a triangulação teórica.

A triangulação metodológica é a mais comumente usada. Vários métodoss ou procedimento de coleta de dados são contidos num mesmo estudo. Aqui incluem-se entrevistas, questionários, observaçôes diretas ou registros de arquivos e evidências físicas. No estudo do desejo de comer, a triangulação metodológica incluiu dados qualitativos provenientes da entrevista semi-estruturada por telefone e quantitativa dos dados levantados do arquivo de cada sujeito do estudo.

Há duas diferentes formas de triangulação metodológica: dentro do método e entre os métodos. A primeira envolve várias formas de obtenção de um mesmo tipo de dado. Um exemplo é o uso de duas ou mais escalas para medida do estado psicológico. O segundo, tem um nível de complexidade maior. Os métodos quantitativos como qualitativos de coleta de dados são usados combinadamente dentro de um mesmo estudo. No estudo sobre o desejo de comer foi utilizada a entrevista semi-estruturada, por telefone, e o levantamento de dados com respostas fechadas contendo várias escalas de medida sobre atitudes acerca do comer, estado psicológico e nível no desejo de comer.

Como já mencionado, há quatro tipos de triangulação. A cada um deles agregamos exemplos oriundos de uma pesquisa relacionada com o desejo de comer. Quando mais de um tipo de triangulação está presente num mesmo estudo, esta forma mais complexa é denominada triangulação múltipla. Contudo, não é necessário que todos os quatro tipos de triangulação estejam presentes num mesmo estudo.

O rigor metodológico, por sua vez, é essencial na triangulação como o é em qualquer método de pesquisa. Na triangulação, há no mínimo quatro princípios básicos a serem seguidos.

O primeiro diz respeito à definição do problema. Isto significa o que o problema, os tipos de dados necessários para sua solução e o método escolhido devem ser cuidadosamente estudados.

O segundo requer que os pontos fracos e os fortes de cada método escolhido complementem-se mutuamente.

O terceiro requer que os métodos sejam selecionados de acordo com sua relevância para a natureza do fenomeno a ser estudado.

O quarto envolve avaliação contínua das abordagens metodológicas escolhidas, durante toda a evolução do estudo, a fim de ser assegurado que os três princípios estejam sendo seguidos.

Os tipos de triangulação e os prinípios de sua aplicação encontram-se claramente definidos. Entretanto, há ainda várias dificuldades quanto ao seu uso e elas referem-se à unidade de análise, às restrições quanto a tempo e gastos, ao preparo dos pesquisadores e à análise de dados (11).

Uma unidade de análise comum que guie o projeto, a coleta e a análise dos dados é requisito básico. O tempo e os gastos financeiros são elevados. Há neces- 
sidade de pesquisadores capacitados tanto em métodos quantitativos como qualitativos. Mas, estas questões parecem ser mais facilmente contornáveis se comparadas àquelas referentes à análise de dados.

A análise dos dados gerados da múltipla triangulação ŝ um problema difícil e ainda não resolvido. Ao contrário, continua a gerar novas questões.

MITCHELL (11) assinala que as dificuldades na análise de dados relacionam-se com:

- combinação de dados numéricos (quantitativos) e dados lingüísticos ou। textuais (qualitativos); lingüísticos;

- interpretação de resultados divergentes entre darlos numéricos e dados;

- análise de conceitos sobrepostos que emergem dos dados e não são ) claramente diferenciados;

- necessidade de ser dado peso às fontes de dados;

- avaliação de diferentes métodos quanto à sua eqüivalência em peso e: possibilidade.

Contudo, estudos sob triangulação vem sendo feitos por outros enfermeiros pesquisadores além de MITCHELL (11).

A triangulação metodológica foi testada por HINDS; YOUNG (9) para estudar o enfermeiro ao prestar cuidado à saúde. Esta pesquisa visou medir os efeitos da instrução padronizada sobre auto-cuidado, ministrada por enfermeiro de saúde pública, e o seguimento dos resultados apresentados por uma população de adultos de mais de 55 anos. Os dados foram obtidos de questionários, observações, relatórios arquivados, notas de campo e entrevistas estruturadas. Segundo as autoras, pela triangulação metodológica foi possível: a) testar as hipóteses do estudo; b) validar os achados do estudo; c) explicar os achados divergentes; d) prover integração teórica; e) obter informações para excluir explicações concorrentes. A convergência entre métodos serviu para aumentar a confiança quanto à adequação dos constructos sobre o cuidado à saúde.

MURPHY (13) usou a triangulação múltipla num estudo sobre desastre natural ocorrido devido erupção do Monte Santa Helena em Washington, EUA, em 1980. A população do estudo constou de grupos de pessoas que tinham sofrido perdas de parentes ou amigos, ou somente de propriedades e que não sofreram perdas. A triangulação múltipla constou de triangulação tanto de dađos, como de pesquisadores, teorias e metodologias. As coletas de dados foram realizadas em duas etapas: uma em 1981 e a outra em 1983. Segundo a autora, a compreensão e a mensuração dos resultados de um desastre natural foram alcançadas graças a triangulação, razão pela qual ela recomenda sua utilização nos estudos sobre eventos traumáticos da vida.

CORNER (3)utilizou a triangulação múltipla para compreender atitudes, conhecimentos, confiança e necessidades educacionais percebidas por enfermeiros recém-registrados no cuidado de pacientes com câncer e para desenvolver e avaliar um pacote educacional que fosse de encontro às necessidades deste grupo profissional. A pesquisa foi desenvolvida em três fases e constou de um estudo exploratório do grupo de enfermeiros, de desenvolvimento do pacote educacional e de avaliação deste pacote. Triangulações de dados de metodologia, de teoria e de pesquisadores foram usados. Ela observou que talvez os pontos de vista filosóficos dos diferentes métodos não sejam passíveis de combinação e que o trata- 
mento superficial de múltiplas fontes de dados impediram a plena e completa abordagem da coleta e análise dos dados. Todavia, observou que a utilização de diferentes métodos provê maior e mais rica compreensão do fenômeno do que se realizada com um único método.

A triangulação múltipla não deve ser apropriada para todos os tipos de pesquisa. Certamente ela não é indicada para pesquisas experimentais altamente controladas com uso de técnicas específicas para aquele experimento. Também não deve ser indicada para pesquisas específicas de uma dada disciplina cujo "design" é restrito dquela disciplina. Entretanto, para muitas questões de pesquisa em enfermagem, tal como em situaçóes nas quais mais de um ponto der vista do fenômeno é desejado, ela parece apropriada; ela ajudaria a explicar o evento, já que oferece flexibilidade e ao mesmo tempo uma abordagem verticalizada.

Em resumo, todos os métodos, usados combinadamente ou não, apresentam vantagens e também, limitações. Enquanto método eles devem ser selecionados apropriadamente, de acordo com a natureza do problema e o que é conhecido acerca do fenómeno a ser estudado. Quanto à crítica ao método ela deve ser dirigida unicamente para a propriedade do mesmo naquela pesquisa $(7,15)$.

As abordagens quantitativas e qualitativas compartilham metas comuns na pesquisa, ou seja, a compreensão do mundo em que vivemos. Considerando esta meta, a adoção de cada uma das abordagens pode ser reconhecida como complementar e a priorização que fica subjacente quando se adota uma ou outra, pode se eliminada como algo não produtivo (8).

A pesquisa precisa de pesquisadores para se tornar real. Os pesquisadores precisam estar treinados nos métodos de pesquisa e isto inclứ toda a extensão.do processo de pesquisa. Os enfermeiros pesquisadores precisam avançar nas habilidades e na compreensão das diferentes abordagens de pesquisa, a fim de capitalizar as forças e os benefícios de cada uma, e atingir mais completa compreensão da prática da enfermagem em toda a sua complexidade.

\section{REFERÊNCIAS BIBLIOGRÁFICAS}

1. BRINK, P. J.: WOOD, M. J. Advanced design in nursing research. Newbury Park, Sage, 1989.

2. BURNS, N.; GROVE, S. K. The practice of nursing research: condut, critique and utilization. Philadelphia, W.B. Saunders, 1987.

3. CORNER., J. In search more complete answer to research questions. Quantitative versus qualitative research methods: is thre a way forward? J. Advanced Nurs., v. 16, p. 718-27, 1991.

4. DEMO, P. Introdução d mètodologia da ciência. São Paulo, Atlas, 1988.

5. DENZIN, N. K. The research act: theoretical introduction to sociological methods. New York, McGraw Hill, 1978.

6. DUFY, M. E. Methodological triangulation: a vehicle for merging quantitative and qualitative research methods. IMAGE, v. 19, n. 3, p. 130-3, 1987.

7. FIELD, P. A.; MORSE, J. Nursing research: the application of qualitative approaches. London, Croom Helm., 1985.

8. HASSE, J. E.; MYERS, S.T. Reconciling paradigm assumptions of qualitative and quantitative research. West. J. Nurs. Res., v. 10, n. 2, p. 128-37, 1988. 
9. HINDS, P. S.; YOUNG, K. J. A triangulation of methods and paradigms to study nurse-given wellness care. Nurs. Res., v. 36, n. 3, p. 195-8, 1987.

10. LÜDGE, V.; ANDRE, M. E. D. A. Pesquisa em educação :abordagens qualitativas. São Paulo, E. P. U., 1986.

11. MIrTCHELL, E. S. Multiple triangulation: a methology for nursing science. ANS, v. 8, n.3, p. 18-26, 1986.

12. MUNHALL, P. L.; OILER, C. J. Nursing research: a qualitative perspective. Norwalk, Appleton-Century-Crofts, 1986.

13. MURPHY, S. A. Multiple triangulation: applications in a program of nursing research. Nurs. Res., v. 38, n.5, p. 294-7, 1989.

14. OMERY, A. Phenomenology: a method for nursing researcl. $A N S$, v. 5, n. 2, p. 49-64, 1983.

15. POLIT, D. F.; HUNGLER, B. P. Nursing research: principles and methods. 3.ed. London, Lippincott, 1987.

16. SANDELOWSKI, M. The problem of rigor in qualitative research. $A N S$, v. 8, n. 3, p. 27-37, 1986. 